\title{
La enseñanza/
}

aprendizaje de los sujetos pronominales en el aula de español como lengua extranjera (ELE) para aprendientes brasileños: teoría y práctica

Silvia Etel Gutiérrez Bottaro

Recebido em: 1 de setembro de 2019 Aceito em: 19 de outubro de 2019

Doctora y Posdoctora por la Facultad de Filosofía, Letras y Ciencias Humanas de la Universidad de San Pablo (USP). Docente de lengua española en el Curso de Letras de la Escuela de Filosofía, Letras y Ciencias Humanas de la Universidad Federal de San Pablo (UNIFESP).

Contacto: etel.sutierrez@unifesp. br Brasil 
PALABRAS CLAVE: pronombres sujeto; lengua española; enseñanzaaprendizaje; abordaje teóricometodológico; estudios comparativos;

\section{KEYWORDS: subject} pronouns; Spanish languase; teaching learning; theoreticalmethodological approach
Resumen: Las investigaciones realizadas sobre el español en Brasil, en los últimos 20 años, se reflejan hoy día en la práctica docente y en la producción de los aprendientes. Parte de estos estudios (González, 1994, 1998, 2008; Groppi, 1997, Yokota, 2001, 2007, 2019; Fanjul, 2014; etc.) se fueron incorporando al referencial teórico de algunos cursos de Letras - Español, conforme lo demuestran los datos recogidos en investigaciones realizadas con alumnos universitarios (Rosa, 2017; Santos, 2019). A partir de esta constatación, por medio de un cuestionario aplicado a los docentes, describimos cómo se realiza el abordaje teóricometodológico sobre la enseñanza de los pronombres sujeto (PS) en algunos cursos de licenciatura de Letras - Español del estado de São Paulo (UFSCAR, USP, UNIFESP), así como también, analizamos algunas de las actividades didácticas aplicadas por los docentes en sus clases.

Abstract: Over the past 20 years, research on the Spanish language conducted in Brazil is reflected today in teaching practice and the production of apprentices. Part of these studies (González, 1994, 1998, 2008; Groppi, 1997; Yokota, 2001, 2007, 2019; Fanjul, 2014; etc.) was incorporated into the theoretical program of some Courses of Letters (Spanish), as evidenced by data collected in research conducted with university students (Rosa 2017; Santos, 2019). From this finding, through a questionnaire applied to teachers, we describe how the theoretical-methodological approach is performed in the teaching of subject pronouns (PS) in some Spanish courses in the state of São Paulo (UFSCAR, USP, and (UNIFESP), as well as analyzing some of the teaching activities applied by teachers in their classes. 


\section{INTRODUCCIÓN}

El contacto lingüístico del español (E) y del portugués brasileño (PB) en el aula de español como lengua extranjera (ELE) en Brasil viene configurando, desde finales del siglo pasado, un gran espacio para las investigaciones comparativas entre esas dos lenguas. Sobre cómo surge este nuevo campo de investigación, González y Fanjul $(2014,11)$ afirman que hasta principios de los años 90 en las universidades no se hacía una reflexión lingüística acerca del español y lo que se fomentaba era solamente la lectura literaria y la formación de profesores para trabajar en las escuelas de idiomas. El marco inicial de los estudios comparativos entre el E y el PB surge en el año 1994, con la tesis doctoral sobre la adquisición/aprendizaje de los pronombres personales por aprendientes brasileños, realizada por la profesora Dra. Neide Maia González. Esta tesis, denominada Cadê o pronome? O gato comeu. Os pronomes pessoais na aquisicáolaprendizagem do espanhol por brasileiros adultos, fue y continúa siendo hasta los días de hoy una importante referencia bibliográfica para muchos de los estudios comparativos que se produjeron en los últimos 20 años, en Brasil y en otros países, así como también lo es para docentes y alumnos de $\mathrm{E}$ interesados en profundizar un tema tan desafiador como es el de los pronombres personales (PP). Entre los estudios existentes que sobrevinieron a la investigación seminal de González acerca de los PP citamos los trabajos de: González (1994, 1998, 2008), Groppi (1997), Yokota (2001; 2007, 2019, Gancedo (2002; 2008), Gutiérrez Bottaro (2009), Simóes (2010; 2015), Fanjul (2014) y, últimamente, los estudios 
de grado realizados por Rosa (2017) y Santos Filho (2019). Parte de estos estudios se fueron incorporando al referencial teórico de algunos cursos de Letras-Español, conforme lo demuestran datos recogidos en investigaciones realizadas con alumnos universitarios. Este hecho parece estar reflejándose en el proceso de enseñanza-aprendizaje de la gramática del español y en la adquisición de los pronombres personales sujeto (PPS). En lo que se refiere a la influencia que ha ejercido la investigación de González en Brasil y los estudios citados anteriormente, Yokota afirma $(2019,87)$ :

Uma vez que a pesquisa de González (1994) teve grande impacto na pesquisa sobre o espanhol no Brasil e repercussóes diretas e indiretas na prática docente, a presença de reflexão sobre as assimetrias inversas passou a fazer parte do conteúdo de muitos cursos de licenciatura em letras-espanhol, de concursos e seleçóes de professores de espanhol para diferentes níveis de ensino, de cursos de formaçáo continuada de professores e de planejamentos e orientaçóes de manuais didáticos. ${ }^{1} \mathrm{Ou}$ seja, a pesquisa de 1994 teve ampla repercussão na formação de professores e na elaboraçáo de seu material de trabalho, o que seguramente se manifesta na formação dos estudantes de espanhol que fazem parte de pesquisas atuais sobre o tema.

Como vemos, de acuerdo con Yokota la reflexión sobre la inversa asimetría, terminología adoptada por González para referirse al diferente comportamiento pronominal que existe entre el $\mathrm{E}$ y el $\mathrm{PB}$, forma parte de los programas de muchos cursos de licenciatura de Letras-Espańol y también está presente en las actividades de algunos manuales didácticos. Como hemos dicho, estudios recientes realizados por Rosa (2017) y Santos

1 Subrayados nuestros. 
LA ENSEN̄ANZA/APRENDIZAJE DE LOS SUJETOS PRONOMINALES EN EL AULA DE ESPAÑOL COMO LENGUA EXTRANJERA (ELE) PARA APRENDIENTES BRASILEÑOS: TEORÍA Y PRÁCTICA

Silvia Etel Gutiérrez Bottaro

Filho (2019), demuestran que esta reflexión teórica realizada en el aula ya se refleja en la producción escrita y oral de los estudiantes de español. Rosa $(2017)^{2}$ en su investigación con alumnos aprendientes de español del curso de letras - español de la UFSCar, pudo constatar un bajo índice de empleo de PS en la producción escrita en comparación con la muestra recogida por González en 1994. Del mismo modo, Santos Filho ${ }^{3}$ analizó en una muestra oral de aprendientes del curso de Letras - Español de la UNIFESP, un elevado número PS nulos, conforme la regla gramatical del E.

A partir de estas últimas e importantes constataciones para el área de estudios de enseñanza y aprendizaje del ELE en Brasil, presentamos aquí parte del trabajo que estamos desarrollando acerca de cómo están repercutiendo algunas investigaciones realizadas sobre temas comparativos entre el $\mathrm{E}$ y el PB en el aula de ELE. En ese sentido, nos propusimos a describir cómo se realiza actualmente la enseñanza teórico-práctica de los PS mediante la reflexión de los estudios comparativos entre el $\mathrm{E}$ y el $\mathrm{PB}$, en algunos cursos de licenciatura de Letras-Español del estado de São Paulo (UFSCAR, USP y UNIFESP). Por medio de un pequeño cuestionario aplicado a los profesores, presentamos el abordaje teórico-metodológico utilizado y algunas de las actividades prácticas impartidas por los docentes en sus clases.

2 Rosa (2017) realizó en su trabajo de conclusión de curso en la UFSCar, una investigación denominada $A$ (não) realização dos pronomes pessoais sujeito em producóes em espahol de graduados brasileiros.

3 Santos Filho (2019) investigó en su trabajo de Iniciação Científica los PS en la producción oral de los aprendientes del curso de Letras-Español de la UNIFESP, el cual denominó O emprego dos pronomes pessoais sujeito nas produçöes orais de aprendizes de língua espanhola como língua estrangeira. 


\section{LA ENSEÑANZA DE LOS PS EN EL AULA DE ESPAÑOL EN LOS CURSOS DE LETRAS-ESPAÑOL}

De acuerdo con las respuestas de los profesores al cuestionario aplicado, la enseñanza de los PS forma parte del programa de lengua española 1, de los tres cursos de licenciatura de Letras-Español (UFSCar, USP y UNIFESP). Además, se lo trabaja a lo largo del curso de español por medio de la identificación de problemas en las actividades de producción escrita, oral y traducciones. Algunos profesores relataron que retoman el tema de los pronombres en el último semestre del curso de español ${ }^{4}$, en el que se trabaja la teoría, desde una perspectiva "más lingüística” y comparativa con el PB. Veamos lo que señaló al respecto uno de los docentes:

(...) Se supone que, en este momento del curso de Letras, el alumno ya está en condiciones de estudiar la lengua desde una perspectiva más lingüistica y que ya dispone de recursos para reflexionar sobre hechos lingüisticos en español. O sea, no se trata de un curso de lengua española a nivel avanzado (como sería en un curso de idiomas), sino de un curso de Sintaxis contrastiva español portugués en un curso de Letras.(Docente 3.1)

Con relación a la teoría gramatical utilizada, todos los docentes dijeron que suelen trabajar con elementos de varias gramáticas: normativa, pedagógica, generativa, sociolingüística, pragmática, pero sobre todo parten de la gramática descriptiva de Bosque y Demonte, con los capítulos de Soriano, Luján y Fontanella de Weinberg (1999), y también de la Nueva Gramática

4 Los docentes informaron que se trabaja el tema desde la perspectiva contrastiva en Língua espanhola 6 y en la asignatura Sintaxe contrastiva espanhol-português.

5 Para identificar y preservar el nombre de los docentes y el de la institución a la cual pertenecen, optamos por denominarlos, aleatoriamente, docente 1, 2, etc. y el otro número corresponde a la institución a la que pertenecen. 
LA ENSEN̄ANZA/APRENDIZAJE DE LOS SUJETOS PRONOMINALES EN EL AULA DE ESPAÑOL COMO LENGUA EXTRANJERA (ELE) PARA APRENDIENTES BRASILEÑOS: TEORÍA Y PRÁCTICA

Silvia Etel Gutiérrez Bottaro

de la Lengua Española (2010). En lo que respecta al abordaje comparativo con el $\mathrm{PB}$, todos respondieron afirmativamente y citaron los trabajos de González (1994, 1998, 2008), Groppi (2006), Fanjul (2014), entre otros. A continuación, citamos algunas de sus respuestas acerca de cómo realizan el abordaje comparativo:

Les voy dando muestras, haciendo hincapié en lo contrastivo entre PB y Ey tratando de trabajar el metalenguaje también (...).(Docente 1.1)

Sí, siempre con todos los temas gramaticales que son claves para el aprendizaje de un estudiante brasileño. (Docente 4.3)

Si, busco siempre abordar los temas de la lengua española desde una perspectiva comparada respecto al portugués brasileño, lengua materna de la casi totalidad de mis alumnos. Utilizo bastante los trabajos de Neide González, que por lo general buscan establecer comparaciones entre el español y el PB; el referencial teórico en dichos trabajos puede variar: la gramática generativa, si se trata de la adquisición de los pronombres por luso hablantes; o la pragmática, si se trata del funcionamiento comparado de los dos sistemas - sobre todo las funciones pragmáticas [tópico, foco, etc.] y la progresión de la información. (Docente 2.1)

Si, tomo las comparaciones hechas por Neide González en su tesis (1994) y en articulos. (Docente 3.1)

Como podemos observar en las respuestas anteriores, los docentes afirman sobre la importancia de trabajar comparativamente temas que traen dificultades a los alumnos, justamente por tratarse de temas asimétricos entre las gramáticas del PB y del E. En el caso de los PS, estos son tratados comparativamente con el $\mathrm{PB}$, desde el primer momento en que los alumnos entran en contacto con el tema en lengua española 1. 
A la pregunta ¿Elabora usted algún material especifico para la enseñanza de los pronombres personales sujeto o utiliza algún material extraido de algún libro didáctico? todos respondieron que suelen preparar sus propios materiales, a partir de materiales auténticos y también de manuales didácticos, siendo que de estos últimos algunos profesores son también sus autores.

En lo que se refiere a la pregunta ¿Cómo aborda el tema por primera vez? la mayoría respondió que parte primeramente de la práctica, o sea, de los usos de la lengua, para luego enseńar la teoría correspondiente; solamente un docente respondió que enseña la práctica y la teoría al mismo tiempo. Para ilustrar cómo se imparten los PS, les solicitamos a los profesores encuestados que adjuntaran alguna de las actividades diseñadas sobre el tema y que utilizan en sus clases.

Antes de describir y analizar las actividades didácticas ${ }^{6}$, es importante presentar de manera sucinta los aspectos teóricos y comparativos acerca del funcionamiento de los PS en el E y el PB, tomando como base parte del referencial teórico que trabajan los docentes encuestados.

\section{Los PS en el E y en el PB: ASPECTOS teóricos descriptivos}

La lengua española permite la ausencia de pronombres sujeto puesto que posee un sistema flexional "rico", es decir, las desinencias del verbo permiten

6 Cabe resaltar que los docentes encuestados gentilmente nos concedieron muchísimos ejemplos de las actividades que trabajan en clase. Sin embargo, por motivos de espacio, presentamos solamente 2 de cada nivel para describir cómo realizan el abordaje teórico-práctico de los PS. 
distinguir las diferentes personas de su paradigma verbal. En la gramática descriptiva, Fernández Soriano $(1999,1224)$ señala:

(...) nuestra lengua difiere de otras, como el inglés, que sólo permiten, con verbos conjugados, construcciones en que el sujeto aparece expresado ( $\mathrm{He}$ saw her). Esta posibilidad, que se da también en italiano y en otras lenguas no emparentadas, se ha puesto en relación con la riqueza que presenta el paradigma verbal, es decir, con el hecho de que la desinencia flexiva del verbo permita, por sí sola, distinguir entre las distintas personas gramaticales ${ }^{7}$.

Según la misma autora $(1999,1225)$, en E se observan tres tipos de sujetos ${ }^{8}$ pronominales ausentes o no explícitos; estos son: 1) los argumentales, cuando tenemos sujetos elididos + un verbo no impersonal, en el que la referencia puede ser indefinida y de cuantificación existencial; estos contrastan con las construcciones con pronombres expresos. Ejemplo: Llaman a la puerta. / Ellos llaman a la puerta. 2) los casi-argumentales, con verbos meteorológicos y otros de tercera persona; el sujeto puede materializarse en expresiones idiomáticas, no obstante, nunca aparece como pronombre. Ejemplos: Llovieron piedras. Llueve una lluvia finita, y 3) los expletivos: son los sujetos de las oraciones impersonales no meteorológicas. Ejemplos: $\varnothing$ Hay moscas en el jardín. Ø Es necesario trabajar más.

Además de estas propiedades, en $\mathrm{E}$ los sujetos pronominales plenos remiten exclusivamente a personas; por esta razón, con objetos el PS está ausente. Ejemplo: He visto el coche de Juan. Ø tiene un color muy bonito.

\footnotetext{
7 Subrayados nuestros.

8 Todos los ejemplos fueron extraídos de Fernández Soriano (1999, 1225 a 1227)
} 
Cabe señalar aquí que el PB, al contrario, hace la referencia a objetos [animados] por medio de un pronombre pleno. Ejemplo: Vi o carro do João. Ele tem uma cor muito bonita.

Por otro lado, en E también existen contextos en que el sujeto pronominal debe estar presente, estos son: 1) cuando el sujeto es foco oracional, este debe tener un acento contrastivo; por lo tanto, no puede recaer sobre morfemas flexivos. Ejemplo: en la pregunta - ¿Quién ha sido? He sido yo $\boldsymbol{y}^{9}$. 2) el sujeto pleno es obligatorio cuando hay complementos apositivos, adjetivales u oraciones; en este caso no puede haber un sujeto elíptico. 3) cuando la forma verbal no consigue diferenciar el referente del sujeto en algunos tiempos verbales en los que coinciden las formas de la primera y tercera persona del singular, como es el caso de los pretéritos imperfecto y el condicional, del modo indicativo, y el presente y pretérito imperfecto del subjuntivo. Ejemplo: Estaba yo viendo la televisión cuando vino tu hermana. (Fernández Soriano, 1999).

Para la mayoría de los gramáticos tradicionales la presencia de un pronombre explícito sujeto es "superflua" y consideran que esta deriva de tres factores: la redundancia, el énfasis y la ambigüedad (Fernández Soriano, 1999). Por este motivo, para Fernández Soriano (1999, 1227), no se puede hablar de una "libre alternancia ni de una opcionalidad", dado que cuando este aparece es porque es necesario y muchas veces deriva de la configuración sintáctica. No obstante, cuando aparece un pronombre tónico en E su presencia se atribuye también a factores de naturaleza más

9 Ejemplos extraídos de Fernández Soriano (1999, 1226) 
discursiva, como el contraste o la individualización. Ejemplos: Tú lo sabias. Yo ya lo he terminado ${ }^{10}$.

Sobre los factores de naturaleza discursiva que están por detrás de los PS, Luján $(1999,1312)$ señala que la presencia del pronombre explícito es "una forma enfática ${ }^{11}$, y debe entenderse como una categoría enfocada, que se contrapone o discrimina con relación a otra que integra el contexto discursivo...". Sin embargo, de acuerdo con la misma autora, en algunos casos la presencia del sujeto no es ni enfática ni contrastiva, sino que es neutral. Por medio de dos ejemplos Luján $(1999,1279)$ explica: (1) Cuando Juan trabaja, él no bebe. En (1) Juan y él tienen distintas referencias, no son las mismas personas. El sujeto pleno tiene como correferente un sintagma nominal más distante que no es Juan. (2) Cuando Juan trabaja, Ø no bebe. En este ejemplo Juan y el sujeto nulo son correferentes (son las mismas personas). El sujeto nulo tiene como correferente el sintagma nominal inmediatamente anterior. Como vemos, según Lujan, cuando el PS está expreso se lo utiliza para indicar que la referencia es distinta a la del sintagma anterior.

El PB al igual que el portugués europeo (PE) también permite omitir los sujetos en algunos contextos. No obstante, algunos estudios (Duarte, 1993, 1995; Kato,1999) comprobaron que el PB está pasando por algunos cambios en lo que se refiere a la realización del sujeto. Por presentar un número elevado de sujetos plenos y un reducido número de sujetos nulos en la lengua hablada, hoy día es considerada una lengua de sujeto nulo parcial.

10 Ejemplos extraídos de Fernández Soriano (1999, 1227)

11 Subrayados nuestros. 
En ese sentido, para Duarte $(1993,1995)$, las características de lengua pro-drop ${ }^{12}$ que el PB presentaba a principios del siglo XIX cambiaron como consecuencia de la simplificación del sistema flexivo verbal.

De acuerdo con las investigaciones, los principales cambios que el PB ha tenido con relación a las formas sujeto en estos últimos tiempos fueron:

1 . Pérdida de la alternancia en el uso del pronombre nulo y lexical típico de las lenguas pro-drop. (Duarte, 1995);

2. Empleo de pronombres plenos en contextos de correferencia con el sujeto de la oración matriz, incluso con antecedente [- humano]: [A casa] virou um filme quando ela teve de ir abaixo. (Duarte, 1993, 1995);

3. Construcciones con sujetos duplicados en el que se retoma un referente esperado y cercano: A Maria ela cozinha muito bem.

4. Pérdida del sujeto nulo referencial: $\boldsymbol{E} \boldsymbol{u}$ não estou conseguindo. (Duarte, 1993, 1995, Galves, 1993, Figueiredo Silva, 1996).

\section{LAS DistintAS ASIMETŔ́AS DEL SUJeTO PRONOMINAL EN EL E y EN EL PB: ASPECTOS COMPARATINOS}

Los aspectos teóricos que hemos visto hasta ahora sobre la realización del sujeto pronominal en el E y en el PB demuestran lo que González (1998) denominó como distinta asimetría en esta área gramatical. Según señaló la misma autora,

12 Término que proviene del inglés y significa lenguas que permiten suprimir el pronombre sujeto. 
LA ENSEN̄ANZA/APRENDIZAJE DE LOS SUJETOS PRONOMINALES EN EL AULA DE ESPAÑOL COMO LENGUA EXTRANJERA (ELE) PARA APRENDIENTES BRASILEÑOS: TEORÍA Y PRÁCTICA

Silvia Etel Gutiérrez Bottaro

(...) es posible asumir la existencia de una diferencia fundamental entre ambas [gramáticas]: cada una de ellas presenta una distinta asimetría en lo que se refiere al empleo de formas pronominales plenas o nulas para la expresión del sujeto y de los complementos del verbo (...) mientras el PB es una lengua de sujeto pronominal predominantemente pleno y que privilegia las categorías vacías o las formas tónicas para la expresión de los complementos, el $\mathbf{E}$ es claramente una lengua de sujetos pronominales predominantemente nulos y de complementos clíticos abundantes, a veces duplicando (o quizás duplicados por) una forma tónica. (González, 1998, 247).

La distinta asimetría en esta área gramatical se refleja muchas veces en la producción de los estudiantes brasileños de E, sobre todo en la de los aprendientes que están en las etapas iniciales. Por tal motivo, es sumamente importante que los docentes de español impartan la lengua haciendo una descripción y reflexión teórica lingüística comparativa de esta área gramatical desde las etapas iniciales, a partir de las distintas teorías gramaticales e investigaciones realizadas en el área de ELE. De este modo, estaremos preparando mejor a nuestros alumnos de los cursos de licenciatura para que entiendan con profundidad el funcionamiento de las dos lenguas en contacto en el proceso de aprendizaje del español por parte de brasileños.

A continuación, presentamos el cuadro realizado por González (2008, 03), adaptado por nosotros para este trabajo, el cual ilustra la distinta asimetría entre las gramáticas del $\mathrm{PB}$ y del E en relación al uso de los PS: 


\begin{tabular}{|c|c|}
\hline Portugués brasileño & Español \\
\hline $\begin{array}{l}\text { 1. En el PB los PS están } \\
\text { predominantemente presentes en parte } \\
\text { por la debilitación de la concordancia, } \\
\text { en parte por una distinta organización } \\
\text { discursiva. Ejemplo: } \\
\text { A Maria disse que ela vai fazer o trabalho } \\
\text { quando ela } \text { puder. }_{\mathrm{i}} \text {. }\end{array}$ & $\begin{array}{l}\text { 1. En E los PS son predominantemente } \\
\text { nulos gracias a la fuerza de la desinencia } \\
\text { verbal, que actúa como un verdadero } \\
\text { pronombre. Ejemplo: } \\
\text { María dijo que [ella] va a hacer el l } \\
\text { trabajo cuando pueda. }\end{array}$ \\
\hline \multirow[t]{2}{*}{$\begin{array}{l}\text { 2. Algunas veces aparecen duplicando un } \\
\text { tópico, con pérdida de valores contrastivos } \\
\text { y una consecuente debilitación del orden } \\
\text { VS. Ejemplo: } \\
\text { O mercado (,) ele está bem aquecido. }\end{array}$} & $\begin{array}{l}\text { 2. Su presencia obedece a necesidades } \\
\text { discursivas y produce efectos, sobre todo } \\
\text { contrastivos. Ejemplo: } \\
\text { Estos muchachos son hermanos: él tiene } \\
\text { veinte años y ella diecicocho. }\end{array}$ \\
\hline & $\begin{array}{l}\text { 3. Sirven para evitar ambigüedades } \\
\text { cuando no es posible recuperar el sujeto } \\
\text { en el contexto. Ejemplo: } \\
\text { No sé decirte por qué, pero todas las tardes } \\
\text { ellaléllyo pasaba horas sin poder hacer } \\
\text { nada. }{ }^{13}\end{array}$ \\
\hline
\end{tabular}

\section{ACTIVIDADES DIDÁCTICAS APLICADAS EN EL AULA SOBRE LOS PS}

Para observar mejor cómo aplican la teoría enseñada y los estudios de investigación realizados sobre los aspectos comparativos entre el E y el $\mathrm{PB}$ les solicitamos también a los docentes que adjuntaran alguna de las actividades que imparten en sus clases sobre el tema que estamos trabajando. A continuación, presentamos algunas de estas actividades:

13 Todos los ejemplos presentes en este cuadro se extrajeron de González $(2008,3)$. 
LA ENSEN̄ANZA/APRENDIZAJE DE LOS SUJETOS PRONOMINALES EN EL AULA DE ESPAÑOL COMO LENGUA EXTRANJERA (ELE) PARA APRENDIENTES BRASILEÑOS: TEORÍA Y PRÁCTICA

Silvia Etel GutiérRez Bottaro

Los Pronombres Sujeto

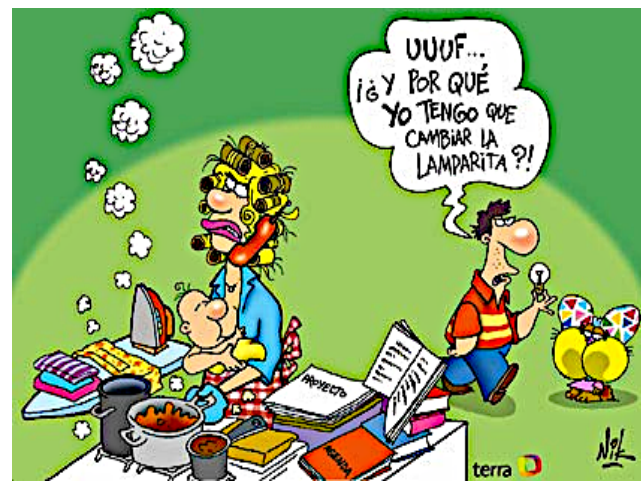

Figura 1. Tira de Gaturro

De acuerdo con la descripción del docente, en esta primera actividad, en la cual se introduce el funcionamiento de los PS en E, por medio de la tira cómica de Gaturro, del historietista argentino Nik, se ilustra uno de los usos de la presencia del PS, que es el de contrastar o individualizar a la persona, en este caso un yo, que está ejerciendo la acción en ese momento. Además, se trabajan también los efectos de sentido que provocan la ausencia y presencia del pronombre yo en la frase enunciada por el marido. Esta actividad es muy importante para que los aprendientes brasileńos entiendan también el funcionamiento discursivo del $\mathrm{E}$ y del $\mathrm{PB}$, desde su primer contacto con la lengua, y no se dejen llevar por el estereotipo de que el E es una lengua fácil y semejante al PB. Son estas semejanzas las que muchas veces conllevan a los alumnos a realizar producciones calcadas en su lengua materna y a 
veces resultan sin sentido en E. Para entender mejor lo que queremos decir, citamos las palabras de González $(2008,4)$ extraídas del artículo también citado por los docentes:

(...) resulta peligroso apoyarse simplemente en el estereotipo de la gran semejanza entre el español y el portugués (en este caso, el de Brasil), porque, aun cuando estas semejanzas existen en un nivel superficial de la lengua, otros factores, tanto de naturaleza propiamente lingüística, gramatical, como de funcionamiento discursivo pueden conducir a errores serios de interpretación o incluso a la incomprensión mutua. Y es importante dejar claro que no se trata simplemente de un conjunto de problemas relacionados con las normas gramaticales vigentes, sino con el funcionamiento de las lenguas y con los elementos indispensables para que se produzca la comprensión por parte de los hablantes nativos y se detecten los sentidos que se producen a partir del uso de determinadas formas.

A continuación, presentamos cómo el mismo docente que aplica la actividad anterior trabaja los aspectos teóricos ${ }^{14}$ sobre el tema:

14 Esta parte teórica, conforme relató el docente, es una adaptación de la Gramática y Práctica de español para brasileños de A. Fanjul (org.) et al (2007). 
LA ENSEÑANZA/APRENDIZAJE DE LOS SUJETOS PRONOMINALES EN EL AULA DE ESPAÑol COMO LENGUA EXTRANJERA (ELE) PARA APRENDIENTES BRASILEÑOS: TEORÍA Y PRÁCTICA

Silvia Etel Gutiérrez Bottaro

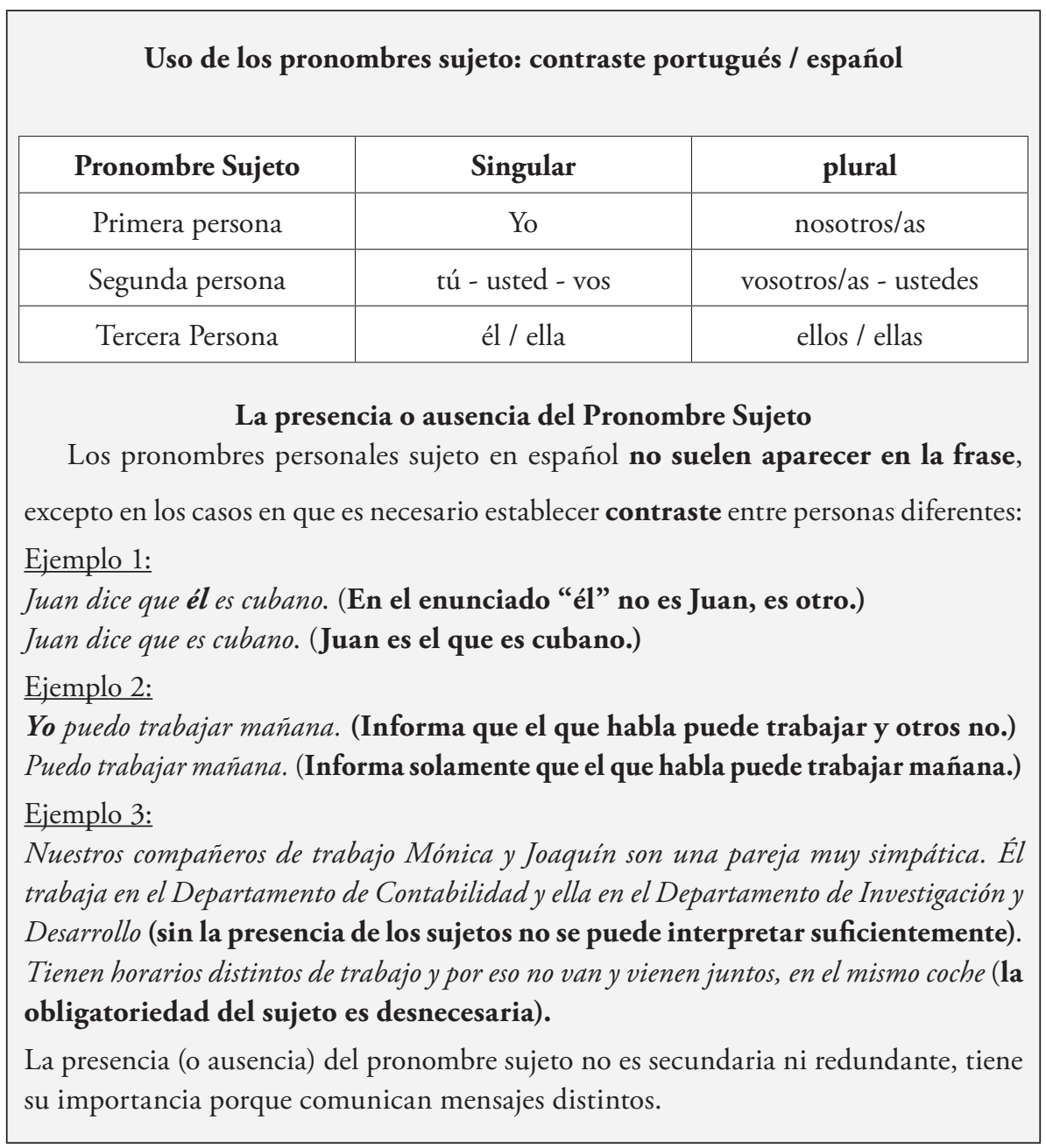

Figura 2. Uso de los PS: Contraste PB/E

En los aspectos teóricos de la sistematización anterior, observamos que desde su título ya se marca el uso contrastivo entre el PB y el E. Por 
medio de ejemplos, se trabajan distintos contextos de uso en los que la presencia/ausencia de los PS se justifica por cuestiones discursivas. Estos mismos usos, como vimos anteriormente, son tratados por Fernández Soriano (1999) y Luján (1999). Así, en el ler ejemplo, en la primera frase con el PS expreso, se quiere demostrar que se lo utiliza para marcar que la referencia de él es distinta a la del sintagma anterior Juan, o sea, es otra persona. Por otro lado, en la segunda frase del 1er ejemplo, la ausencia del PS está indicando que el sujeto nulo tiene como correferente el sintagma nominal inmediatamente anterior, en este caso Juan (Luján 1999, 1279). En el $2^{\circ}$ ejemplo, la presencia del pronombre en la primera frase está indicando el uso contrastivo; por otro lado, en la segunda frase, como no hay necesidad de contraste el PS está ausente. En el 3er ejemplo, lo que se quiere demostrar con la primera frase es que la presencia es obligatoria cuando los sujetos son foco oracional, con acento contrastivo, por esta razón no puede recaer sobre la flexión verbal (Fernández Soriano, 1999, 1225). En la segunda frase de este mismo ejemplo, la presencia de los sujetos pronominales ya no es más obligatoria, puesto que sus correferentes están próximos en las frases anteriores. Al final de la exposición teórica, se encierra la explicación enfatizando que la presencia o ausencia de los PS en la frase es importante porque cuando estos están expresos o no en la frase “comunican mensajes distintos”. En ese sentido, Fernández Soriano (1999, 1227) afirma que “(...) no hay alternancia entre el uso y la omisión de los pronombres sujeto. (...)todo parece indicar que un pronombre no es redundante, sino totalmente imposible en algunos casos.” 
LA ENSEN̄ANZA/APRENDIZAJE DE LOS SUJETOS PRONOMINALES EN EL AULA DE ESPAÑOL COMO LENGUA EXTRANJERA (ELE) PARA APRENDIENTES BRASILEÑOS: TEORÍA Y PRÁCTICA

Silvia Etel GutiérRez Bottaro

1. A la luz de las explicaciones de los distintos materiales, explica la reacción de Mafalda en la siguiente tira:

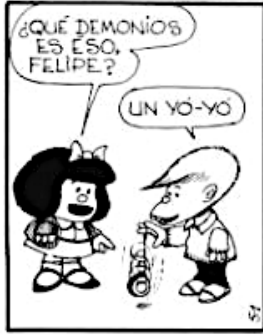

i3
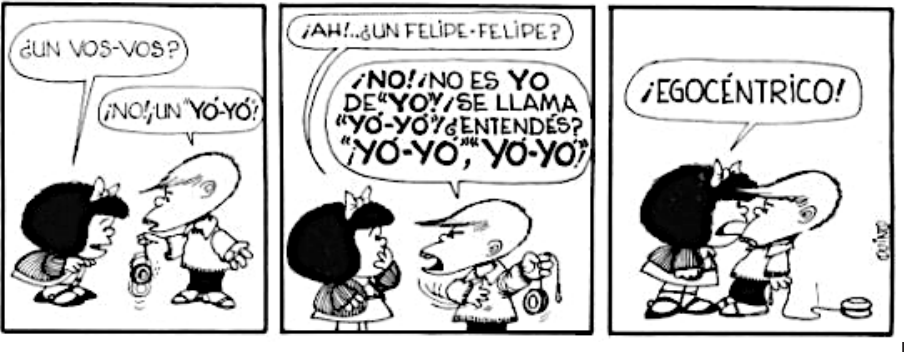

Figura 3. Tira de Mafalda

En esta actividad observamos que el docente que la diseñó ya ha trabajado anteriormente los aspectos teóricos sobre el tema y les presenta a los alumnos esta tira de Mafalda, de Quino, como una muestra de los usos de los PS en E. Vemos que Mafalda está asociando el nombre del juguete yo-yo con la $1^{\mathrm{a}}$ persona del PS con el valor que se le atribuye discursivamente a los PS cuando se lo usa con la función de individualizar o enfatizar. Felipe, el amiguito de Mafalda, intenta explicárselo varias veces hasta que al final se enoja y se lo explica de una manera muy enfática: yó -yó. Mafalda sigue entendiendo que el nombre está asociado al yo (personal) de Felipe y se enoja tanto que termina llamándolo egocéntrico. Por medio de este ejemplo, vemos una vez más que el funcionamiento del pronombre pleno en la frase se debe a factores de naturaleza más discursiva, en este caso énfasis o individualización. Por este motivo creemos, al igual que González $(2008,5)$, que el docente 
debe desarrollar “(...) un grado de reflexión pragmático-discursiva que le permita dar cuenta del espesor de la materialidad lingüística en lo que hace al sentido, de modo de comprender mejor la complejidad del proceso de aprendizaje de una lengua extranjera".

Observa los sujetos pronominales en el siguiente anuncio y responde:

1) ¿Qué función cumplen los sujetos expresos?

2) ¿En lugar de los pronombres nulos podríamos usar un pronombre sujeto?

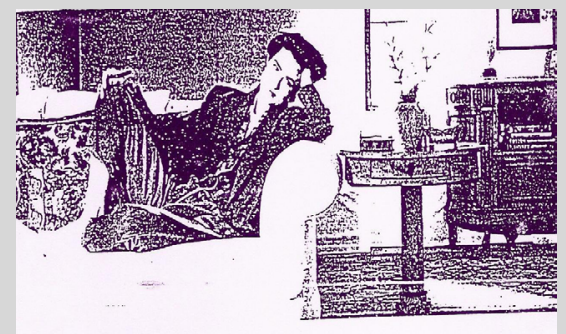

Mi padre me proporcionó clases de equitación y de golf. (10) le regalé una corbata.

(6) ne enviṕ a hacer un post-grado en Paris Yo) le regalé una camisa.

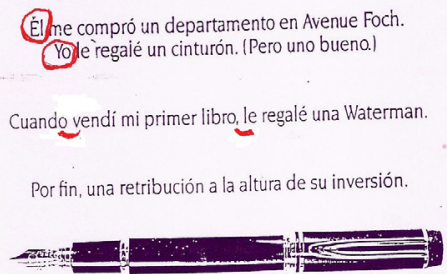

Figura 4. Anuncio 
Como hemos dicho anteriormente, los docentes relataron que vuelven a trabajar con más profundidad los aspectos teóricos ${ }^{15}$, desde una perspectiva más lingüística, en los cursos superiores. Vimos también que se trata de cursos en los cuales se trabaja la sintaxis y tópicos contrastivos entre el E y el PB. Por medio de este anuncio publicitario, se les pregunta a los aprendientes qué función cumplen los PS expresos y nulos de la última frase. Las respuestas a la primera pregunta son las siguientes: en la $\mathbf{1}^{\mathbf{a}}$ oración, Mi padre me proporcionó ... Yo le regalé una corbata, vemos que el contexto discursivo de este anuncio requiere la presencia del sujeto explícito para contrastar, en este caso, los regalos que se dan un padre y una hija en este anuncio. Recordando la teoría, conforme Luján (1999), los PS aparecen de forma explícita como una categoría enfocada para contraponerse con otra que integra el contexto discursivo. En la $\mathbf{2}^{\mathbf{a}}$ oración, Él me envió a hacer un post-grado en París. Yo le regalé una camisa, vemos que el sujeto de $1^{\mathrm{a}}$ persona correferencial nuevamente es contrapuesto al de $3^{\text {a }}$ persona para contrastar, enfatizar los regalos que se dan el padre y la hija. Todos los pronombres sujeto él retoman el mismo antecedente, el SN Mi padre, o sea, son correferentes y cumplen la misma función discursiva que es la de contrastar con un yo. A la pregunta si se podría usar el pleno yo en lugar de los nulos en la $3^{\mathbf{a}}$ oración, Cuando _ vendi mi primer libro, _ le regalé una Waterman, la respuesta es negativa, pues la intención de la hija al final del anuncio ya no es más la de

15 Los docentes citaron los trabajos de Fernández Soriano (1999) y Luján (1999), el capítulo que trabaja los pronombres personales de la Nueva gramática de la lengua española (2009), y sobre todo los artículos de González (1998, 2008) y Fanjul (2014). 
seguir contrastando los regalos que ambos se daban, con su nuevo estatus de escritora, y con este último regalo, una lapicera de marca, ya estaría a la altura de todos los regalos que le hizo su padre.

$4^{\circ}$ EJEMPLO DE ACTIVIDAD DIDÁCTICA TRABAJADA EN EL AULA DE SINTAXE CONTRASTIVA ESPANHOLPORTUGUES:

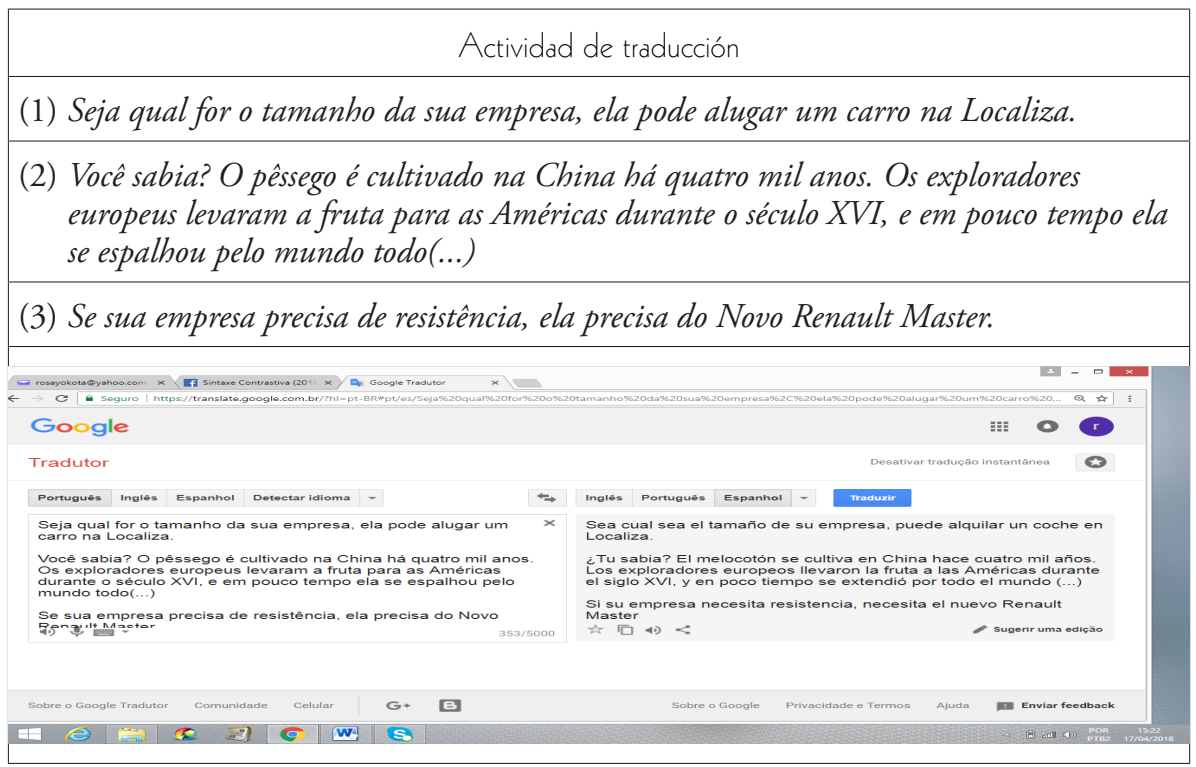

Figura 5. Actividad con traductor electrónico.

Para trabajar la comparación entre el PB y el E los docentes informaron también que diseñan actividades de traducción, sobre todo en los cursos superiores. Los alumnos las hacen como tarea domiciliar y luego en clase se 
hace la corrección comentada. Una actividad muy interesante que se realiza es que se comparan los resultados de la traducción también por medio de traducciones hechas en el traductor electrónico. Conforme señaló el docente: “poner traducciones hechas por medio del traductor electrónico les permite ver que esta es una herramienta que pueden usar, pero deben revisar muy bien los resultados y hacer adecuaciones".

En la actividad de traducción realizada por medio del traductor electrónico en el ejemplo $4^{\circ}$, observamos una vez más claramente las diferencias entre el funcionamiento de los PS en ambas lenguas. Conforme vimos, el $\mathrm{PB}$ permite emplear los sujetos plenos para retomar antecedentes [-animado]. Este uso lo observamos en las frases (1) y (3) del PB, en las cuales el pronombre ela hace referencia al objeto empresa y en la frase (2) ela remite a fruta. En las mismas frases traducidas al E, esta regla no se aplica, puesto que en E los PS remiten exclusivamente a personas [+ animados]. En la misma frase (2) en PB, se observa otro de los usos del PB al estar el PS você expreso en la pregunta você sabia?. Sin embargo, en la traducción al E, ¿tu sabia?, realizada por el traductor electrónico, se hace una transferencia del sistema pronominal del $\mathrm{PB}$, pues como sabemos en este caso en E el PS sería nulo, dado que la flexión verbal identifica al sujeto, sin haber necesidad de usar el pronombre expreso. Como vemos, en este caso se tuvo que adecuar esta traducción a las reglas del E, puesto que el pronombre sujeto tú fue traducido sin tilde y el verbo saber fue traducido a la $3^{a}$ persona del singular y sin tilde; la traducción correcta sería: (tú) sabías. Sobre esta misma frase, cabe señalar que en lugar de 
un tú nulo, se podría traducir este tú por un usted, sólo que en este caso el E permite el empleo de un usted pleno: ¿usted sabía o sabía usted?. Este uso pleno se justifica para evitar la ambigüedad verbal, dado que algunas flexiones del verbo no diferencian el referente del sujeto porque las desinencias de la $1^{\text {a }}$ persona y las $3^{\text {a }}$ personas del singular (él, ella y usted) son iguales.

\section{CONSIDERACIONES FINALES}

En este artículo vimos que algunos estudios recientes -Rosa (2017) y Santos (2019)-están demostrando que las investigaciones sobre la enseñanza del español en Brasil se reflejan en la práctica docente y, sobre todo, en la producción de los aprendices brasileños de español. Esta constatación nos llevó a preguntarnos cómo se imparte el tema de la enseñanza de las formas pronominales sujeto del $\mathrm{E}$ en algunos cursos de licenciatura de español. Nuestro objetivo ha sido investigar cómo los docentes en los cursos de formación de profesores de español realizan el abordaje teórico-metodológico sobre un tema gramatical considerado asimétrico entre el E y el PB. Para esto, describimos el referencial teórico que se imparte en las clases y las actividades didácticas diseñadas por los docentes.

Las respuestas de los docentes al cuestionario aplicado y las actividades didácticas que estos desarrollan en el aula con los aprendientes revelaron que la enseñanza llevada a cabo en los cursos de Letras-Español no sólo no prescinden de las reflexiones propiciadas por las investigaciones realizadas 
LA ENSEN̄ANZA/APRENDIZAJE DE LOS SUJETOS PRONOMINALES EN EL AULA DE ESPAÑOL COMO LENGUA EXTRANJERA (ELE) PARA APRENDIENTES BRASILEŃOS: TEORÍA Y PRÁCTICA

Silvia Etel Gutiérrez Bottaro

sobre el español en Brasil, como también se instiga a que los estudiantes, futuros profesores de ELE, investiguen y busquen respuestas a sus interrogantes lingüísticos y discursivos, inspirados en un modelo didáctico reflexivo y comparativo. Al igual que Yokota $(2019,88)$, creemos que $O$ ensino sensibiliza o aprendiz para questóes sintáticas, pragmáticas e discursivas que não estavam presentes em cursos anteriores aos anos 90, possibilitando que o processo de aprendizagem do estudante brasileiro tenha um percurso que o aproxima cada vez mais do E.

\section{REFERENCIAS BiBLIOGRÁFICAS}

Duarte, Magnolia. L. "Do pronome nulo ao pronome pleno: a trajetória do sujeito no português do Brasil”. In: Roberts, I.; Kato, M. (Coords.). Português brasileiro: uma viagem diacrônica. Campinas: Editora da UNICAMP, 1993.

Duarte, Magnolia. L. A perda do Princípio "Evite Pronome" no Português Brasileiro. Tese (Doutorado em Estudos da Linguagem) - Instituto de Estudos da Linguagem, UNICAMP. Campinas, 1995.

Fanjul, Adrián P. "Conhecendo assimetrias: a ocorrência de pronomes pessoais". In: Fanjul, Adrián. P.; González, Neide. M. (Org.) Espanhol e português brasileiro: estudos comparados. São Paulo: Parábola, 2014.

Groppi, Mirta. Os pronomes pessoais no espanhol do Uruguai e no português do Brasil. Tese (Doutorado em Filologia e Língua Portuguesa) - FFLCH, USP. São Paulo, 1997.

Yokota, Rosa. A marcação de caso acusativo na interlíngua de brasileiros que estudam o espanhol. Dissertação de Mestrado, FFLCH, USP. São Paulo, 2001.

Yokota, Rosa. O que eu falo não se escreve. E o que en escrevo alguém fala? A variabilidade no uso do objeto direto anafórico na produçáo oral e escrita de 
aprendizes brasileiros de espanhol. 2007. Tese (Doutorado em Letras) -FFLCH, USP. São Paulo, 2007.

Yokota, Rosa. "A pesquisa sobre assimetrias inversas e seus reflexos no ensino e na aprendizagem de espanhol por brasileiros: as formas tônicas". In: Bruno, F.A.T.C; Pinheiro-Correa, P.; Yokota, R. (Orgs.) Cadê o pronome que estava aqui? Homenagem a Neide González: Campinas, SP: Pontes, 2019.

Fernández Soriano, Olga. "El pronombre personal. Formas y distribuciones. Pronombres átonos y tónicos”. In: Bosque, I.; Demonte, V. (Org.) Gramática descriptiva de la lengua española. Madrid: Espasa-Calpe, 1999.

Figueiredo Silva, M. C. A posição sujeito no português brasileiro: frases finitas e infinitivas. Campinas, São Paulo: Editora da UNICAMP, 1996.

Fontanella de Weinberg, María B. "Sistemas pronominales de tratamiento usados en el mundo hispánico”. In: Bosque, I., Demonte, V. (Org.) Gramática descriptiva de la lengua española (Vol. 1 Sintaxis básicas de las clases de palabras). Madrid: Espasa Calpe, 1999.

Galves, Charlotte. "O Enfraquecimento da Concordância no Português Brasileiro". In: Roberts, I.; Kato, M. (Coords.). Português Brasileiro: uma viagem diacrônica. Campinas: Editora da UNICAMP, 1993.

Gancedo, Alicia. La oblicuidad, construçôes de dativos na interlíngua de estudantes brasileiros de espanhol. Dissertação de Mestrado, FFLCH, USP. São Paulo, 2002.

Gancedo, Alicia. Consequências sintáticas e semânticas das relaçóes de possessão em espanhol e na produção não nativa de brasileiros. Tese (Doutorado em Letras) -FFLCH, USP. São Paulo, 2008.

González, Neide M. "Portugués brasileño y español: lenguas inversamente asimétricas". In: Celada, M.T. y González, N. M. (eds.). In: Gestos que trazan distinciones entre la lengua española y el portugués brasileño. SIGNOS ELE 2.2 (diciembre), 2008. Disponible en: <http://www.salvador.edu.ar/signos/ele>. Acceso en junio de 2019. 
LA ENSEN̄ANZA/APRENDIZAJE DE LOS SUJETOS PRONOMINALES EN EL AULA DE ESPAÑOL COMO LENGUA EXTRANJERA (ELE) PARA APRENDIENTES BRASILEÑOS: TEORÍA Y PRÁCTICA

Silvia Etel Gutiérrez Bottaro

González, Neide M. Cadê o pronome? O gato comeu. Os pronomes pessoais na aquisição/aprendizagem do espanhol por brasileiros adultos. 1994. 461f. Tese (Doutorado em Semiótica e Linguística Geral) - FFLCH, USP. São Paulo, 1994.

González, Neide M. "Pero ¿Qué gramática es ésta? Los sujetos pronominales y los clíticos en la interlengua de brasileños adultos aprendices de español/ LE”. In: Revista Rilce,.14.2, 243-263, 1998.

Gutiérrez Bottaro, Silvia. E. O sujeito pronominal no portugués uruguaio da regiáo fronteiriça Brasil - Uruguai. Tese (Doutorado em Letras) - FFLCH, USP. São Paulo, 2009.

Kato, Mary. "Questōes atuais da aquisição de L1 na perspectiva da teoria de princípios e parâmetros”. In: Cadernos de Estudos Lingüisticos. Campinas, São Paulo: n. 36, 11-16, 1999.

Luján, Marta. "Expresión y omisión del pronombre personal". In: Bosque, I.; Demonte, V. (Org.) Gramática descriptiva de la lengua española. Madrid: Espasa-Calpe, 1999.

Real Academia Española y Asociación de Academias Americanas. Manual de la Nueva Gramática de la Lengua Española. Madrid: Espasa-Calpe, 2010.

Rosa, Jéssica R. A (não) realização dos pronomes pessoais sujeito em produçóes em espanhol de graduados brasileiros. Trabalho de Conclusão de Curso (Licenciatura em Letras - Português/Espanhol) - UFSCar. São Carlos, 2017.

Santos Filho, Jarbas I. O emprego dos pronomes pessoais sujeito nas produçóes orais de aprendizes de lingua espanhola como lingua estrangeira. Trabalho de Iniciação Cientifica (Licenciatura em Letras - Português/Espanhol) - UNIFESP. Guarulhos, 2019.

Simôes, Adriana M. Clítico, objeto nulo ou pronome tônico? Quanto e como a variaçãol mudança no paradigma do preenchimento pronominal do objeto acusativo de $3^{a}$ pessoa no português brasileiro se reflete na aquisiçãolaprendizagem do espanhol pelos aprendizes brasileiros ao longo das geraçóes. Dissertação de Mestrado, FFLCH, USP. São Paulo, 2010. 
Simóes, Adriana M. O objeto pronominal acusativo de 3 a pessoa nas variedades de espanhol de Madri e Montevidéu comparado ao português brasileiro: clíticos como manifestação visivel e objetos nulos como manifestação não visivel da concordância de objeto. Tese (Doutorado em Letras) - FFLCH, USP. São Paulo, 2015. 